\title{
A Method of Estimating the Personal Ideology of Political Representatives
}

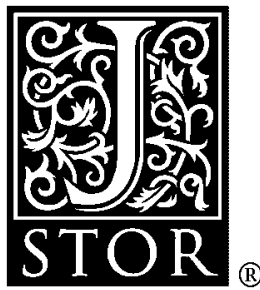

\author{
Richard T. Carson; Joe A. Oppenheimer \\ The American Political Science Review, Vol. 78, No. 1. (Mar., 1984), pp. 163-178.
}

Stable URL:

http://links.jstor.org/sici?sici=0003-0554\%28198403\%2978\%3A1\%3C163\%3AAMOETP\%3E2.0.CO\%3B2-B

The American Political Science Review is currently published by American Political Science Association.

Your use of the JSTOR archive indicates your acceptance of JSTOR's Terms and Conditions of Use, available at

http://www.jstor.org/about/terms.html. JSTOR's Terms and Conditions of Use provides, in part, that unless you have obtained prior permission, you may not download an entire issue of a journal or multiple copies of articles, and you may use content in the JSTOR archive only for your personal, non-commercial use.

Please contact the publisher regarding any further use of this work. Publisher contact information may be obtained at http://www.jstor.org/journals/apsa.html.

Each copy of any part of a JSTOR transmission must contain the same copyright notice that appears on the screen or printed page of such transmission.

The JSTOR Archive is a trusted digital repository providing for long-term preservation and access to leading academic journals and scholarly literature from around the world. The Archive is supported by libraries, scholarly societies, publishers, and foundations. It is an initiative of JSTOR, a not-for-profit organization with a mission to help the scholarly community take advantage of advances in technology. For more information regarding JSTOR, please contact support@ jstor.org. 


\title{
A Method of Estimating the Personal Ideology of Political Representatives
}

\author{
RichaRd T. CARSON \\ University of California, Berkeley \\ JOE A. OPPENHEIMER \\ University of Maryland
}

\begin{abstract}
We suggest a method for estimating a political representative's personal ideology and its effect on his or her voting decisions. The current practice of using the ratings of a pressure group such as Americans for Democratic Action (ADA) as a proxy for personal ideology is shown to have a number of theoretical and interpretive flaws. Our technique uses the residuals from two regression equations to provide answers to two questions: Is there a systematic ideological component to the voting behavior of political representatives after taking account of other political determinants, and if a systematic ideological component exists, is it possible to determine its role in voting on particular issues? The technique developed and the currently accepted practice are compared using votes on labor issues as an empirical example.
\end{abstract}

Legislative voting has long been a subject central to modern American political science. Recently, economists have also become active in this field of study. Over the years a number of alternative models have been proposed to explain legislative voting, and a rough consensus has developed on the identity of the major determinants of voting (Kingdon, 1977). In most models ideology plays a role in determining the legislator's voting pattern. The ensuing pages attempt to convince the reader both that there is something wrong with the way ideology has usually been measured and that our procedure constitutes a substantially improved measure for ideology. The argument of this article is consistent with virtually any theoretical model of legislative behavior which gives ideology a place.

To illustrate and test our procedure, it will be

Received: March 7, 1983

Accepted for Publication: June 23, 1983

Our appreciation is given to Resources for the Future for its continued support for this research and to the Alfred P. Sloane Foundation, which generously funded our work on marketable permits through a grant made to Resources for the Future for the study of "Alternatives to Direct Regulation." This work grew directly out of research on that project. We are indebted to Robert Mitchell who ably critiqued and helped us with the development of these ideas. Laura Quinn is responsible for excellent research assistance. Our gratitude is also extended to Peggy Conway, Norman Frohlich, John Mullahy, Charles Phillips, Warren Phillips, Cliff Russell, and Eric Uslaner for their extensive and helpful comments. necessary to apply our argument within the context of a specific theoretical approach to legislative voting. Our applications are to models that picture the representative's voting act as a political act in which a career politician attempts to further his security, and his stature, by strategically choosing how to vote. ${ }^{\prime}$ Such a model assumes that the individual legislator is motivated by whatever gives electoral, or more broadly, political, security. ${ }^{2}$ But such a political view of the legislator is incomplete, for legislators also have personal views and values which enter into their voting decisions (cf. Wittman, 1977). ${ }^{3}$

Normally legislative voting is seen as a function of the representative's political and ideological constraints, i.e., the representative's party, the

'One can point to some of the alternative models put forward in the congressional voting literature. For example, it has been suggested that representatives vote by taking cues from their colleagues, and in particular it has been shown that representatives tend to vote with both their state colleagues and others with whom they find themselves in ideological agreement (Kingdon, 1977; Weisberg, 1978). Other variables that are often considered stem from the Washington, or more specifically, the legislative environment and characteristics of the legislator's electoral coalition (Kushner, 1975; Markus, 1974). Such analyses may indeed be correct and not inconsistent with what we are proposing. Quite the contrary, some shall be shown merely to require a more complex system of equations for tests.

${ }^{2} \mathrm{~A}$ number of analysts have argued this position with varying degrees of dissent from its assumptions. See, for example, Chappell (1981a, b), Kau and Rubin (1979a, b), Mayhew (1974), and Silberman and Durden (1976). 
socioeconomic (or political) characteristics of the legislator's constituents and other supporters, and the legislator's own ideology. ${ }^{4}$ In many of these studies, there appears to be considerable agreement on how to measure ideology. Ideology is usually operationalized by the use of one or another of a number of "ratings" by pressure groups. (See, for example, Bernstein \& Horn, 1981; Chappell, 1981a, b; Kalt, 1981, 1982; Kenski \& Kenski, 1980; Lopreato \& Smoller, 1978; MacRae, 1970; Matthews, 1960.) Our argument is not for or against any one particular paradigm, nor with the inclusion of ideology as a determinant of the incumbent's voting patterns, but rather with the method used to measure ideology."

Pressure group "ratings" are usually calculated simply as the percentage of the time the legislator voted "with" the pressure group on a specific subset of roll call votes during a particular session. Thus, part of the incumbent's voting record is used as an indicator of ideology. Ideology is then used to explain voting on some other matters. This method creates difficulties of interpretation because we are explaining a set of votes (e.g., on labor issues) by a (perhaps disjoint) second set of votes which are taking place over the same period of time and are theoretically simultaneously determined by the same factors. More generally, the measure of the independent variable, ideology, is itself explained by the same variables as is the dependent variable. For example, if one were interested in explaining voting behavior

${ }^{3}$ There is, however, a tradition, especially in the public choice school, to discount (totally) the personal values of the politicians (e.g., Downs, 1957). The results reported in the fourth part of this article can be seen as a (disconfirming) test of this hypothesis.

${ }^{4}$ The factors that are indicated are usually part of the explanatory variables utilized in legislative voting studies. See, for example, Lopreato and Smoller (1978). Note that it could be that voting is not determined by district characteristics, but rather only by those elements (of or beyond the district) which are selected to be in the legislator's coalition. Note that the coalition would filter both the voters and the interest groups which support the legislator. This is the implication of the work of Markus (1974) and Kushner (1975) and is supported by various public choice models such as that by Oppenheimer (1975).

'Usually the personal ideology of a legislator is taken to be reflected in the ratings of that legislator by the Americans for Democratic Action (ADA). But the indices of various groups are highly correlated with each other (which they should be, theoretically, if there is an overall model governing voting behavior) (Poole, 1981). We accept the usual convention of ideology along the liberal-conservative dimension. There are, of course, other dimensions which could be defined. The arguments presented in this article are adaptive. on, let's say, labor issues, one could estimate COPE $^{6}$ scores as a function of the individual's party $\left(P_{i}\right)$, district $\left(D_{i}\right)$, personal position within the legislature $\left(L P_{i}\right)$, and ideology $\left(I_{i}\right)$.

Now COPE scores are highly correlated with such standard measures of ideology as the ratings bestowed on members of Congress by the Americans for Democratic Action (ADA) and by the conservative pressure group, the Americans for Constitutional Action (ACA). ${ }^{7}$ Further, since the ADA score, or another proxy for ideology, is simultaneously determined with the dependent variable (COPE), other problems may follow. For example, using ADA as a measure for ideology could cause the other variables to be counted twice-once directly and once through their role in determining ADA. Thus, it is obvious that while the ADA rating (ADA) is correlated with $I$ (and hence a possible proxy for $I$ ), it is also correlated with everything else in the equation, giving rise to problems of extreme multicollinearity (and its associated problems-large standard errors in parameter estimates and unreliable tests of significance). Thus, Fiorina (1979) noted, in a critique of an article that used this practice:

\begin{abstract}
The explanatory variable, liberalism, is measured by the Americans for Democratic Action index. Since the roll call votes that compose the latter are presumably functions of party and constituency as well as ideological influences, it is difficult to treat the summed score as a measure of liberalism alone but .... (the authors) show no great concern over this (p. 50).
\end{abstract}

Therefore, when the researcher correlates (for example) an individual's ADA rating with his or her voting on some other issues and reports that correlation as indicating the role of ideology in the incumbent's voting, the ideology is given weights which, at least, are noninterpretable and probably are vastly overstated. Other variables are also assigned peculiar weights.

'Here COPE is the AFL-CIO's rating of the legislator. These scores indicate the percentage of the time that the legislator voted "with" the interests of the AFL-CIO on issues selected by the unions.

'For example, Kau and Rubin (1979a, p. 369) report the correlations as follows for 1973: $r(\mathrm{COPE}, \mathrm{ADA})=$ $.85, r(\mathrm{COPE}, \mathrm{ACA})=-.89$, and $r(\mathrm{ACA}, \mathrm{ADA})=$ -.90 . Similarly, in our data (see the third and fourth sections below), $r$ (COPE,ADA) $=.86$.

${ }^{8}$ Ridker and Henning's (1967) problem was that one of their independent variables incorporated the effects of air pollution on property values, the item they wished to measure. Johannes and McAdams develop a residualized ADA variable to measure the representative's deviation from the district's ideological position, as measured by its pro-McGovern vote in 1972 . 
Indeed, researchers have noticed in their studies that personal ideology was "weighing in" heavily, and that their findings did not reflect normally perceived wisdom (e.g., Bernstein \& Horn, 1981; Dunlop \& Allen, 1976; Kenski \& Kenski, 1980). Theoretically, utilizing ADA as a direct measure of personal ideology double-enters all the district characteristics (once indirectly, via ADA) and consequently makes all the other coefficients less significant than expected. Thus, such a measure poses a number of difficulties of interpretation for the researcher.

Recently, Kalt (1982) grappled with the problem quite directly. In trying to explain "a variable PROCRUDE [which] reflect[s] the frequencies . . . with which [a] senator casts a vote favorable to crude oil producers" (p. 149), he utilizes both the senator's ADA score (as an indicator of ideology), and a few energy related characteristics of the state's economy. Kalt begins the discussion of his results with a warning: "PROADA [the ADA score] might be thought of as the outcome of a stochastic process of the general type that produced PROCRUDE"' (p. 155). He probes this possibility as follows: "If there were a systematic relationship between PROCRUDE and the stochastic element in PROADA, a two-stage simultaneous equations technique would be warranted. ... [But] none of the results at any step of the analysis proved to be at all sensitive to this adjustment. Thus, two-stage results are not reported here"' (p. 155).

Kalt was on to the problem. Indeed, he found ideology to be by far the most important variable in the determination of PROCRUDE (1981, pp. 265-268). The problem is not, however, a simultaneous determination of PROCRUDE and PROADA with PROADA being a determinant of PROCRUDE. Rather we conjecture there are underlying factors which are the major determinants of both PROCRUDE and PROADA. Kalt can be defended for his procedure since he regressed PROADA on party and the socioeconomic characteristics of the district and realized that PROADA was largely determined by those factors (1981, p. 266). Kalt, who did not conceptualize PROADA as personal ideology $(1981$, p. 260$)$ did not probe the linkage further.

Matthews (1960, pp. 133-135) may have been the first to have sophisticated thoughts about how to rectify these sorts of problems, although he did so with an eye to party loyalty, not ideology. As MacRae (1970, p. 253) puts it:

Matthews, wishing to measure the party effort of individual senators independently of their general liberalism or conservatism, used the method of residuals from a regression line to make this separation. He first plotted the party unity index values, for the senators of a given party, against their conservatism-liberalism scores. . . . He then used the residuals of party unity, after the contributions of liberalism had been controlled or removed by a regression equation, as a purer index of partisanship (emphasis added).

This leads MacRae to conclude (p. 253), "Matthews's reasoning suggests a line of investigation which still remains promising."

Most recently, Kau and Rubin (1979a) and Johannes and McAdams (1981) have built on Ridker and Henning (1967) to "residualize" the traditional (ADA) index of ideology. ${ }^{8}$ As Kau and Rubin put it, in their study of how economic influence determines congressional voting:

To the extent that ADA does measure economic influence, including it in equations where the economic variables are already present may result in multicollinearity. Leaving ADA out would lead to the improper exclusion of ideology. A solution of this problem is to replace ADA with another variable, RADA, that is orthogonal to the economic variables. This new variable is obtained by subtracting from the actual values of ADA the computed values obtained from the ratings equations. The observations on RADA are the residuals. . . . This procedure eliminates multicollinearity between ADA and the economic variables. The coefficients of the economic variables are the same as they would have been had ADA not been included. The coefficient of RADA is unaffected by this procedure. It is of course possible that we have omitted variables from the specification; . . . this problem always exists in empirical work. However, the residualization technique does not amplify this problem. (pp. 370-372)

We shall argue below that with some changes the residualization technique is a useful, standardizable, approach to the problem. We shall apply it to a study of labor votes in the Senate to illustrate its general properties. Note that part of the difficulty with the original measures stems from the non-observable (directly) nature of the personally held values segment of the representative's ideology. What is needed is a proxy for this nonobservable segment of ideology, i.e., personal ideology. ${ }^{9}$ To understand how personal ideology

\footnotetext{
${ }^{9}$ The problem of unobserved variables has long been recognized as a problem of identification in the econometrics literature (see Goldberger, 1964). For a discussion of treatment of unobserved variables and other statistical procedures used in this article, such as probit analysis and simultaneous equations, from a readable social science perspective, the reader is referred to Haunshek and Jackson (1977).
} 
can be measured by the residualization technique, we need to see how using the "residualized" ADA works.

\section{A Residualized Measure of Ideology}

To develop our analysis, consider a representative's vote $\left(V_{i}\right)$ on any issue $(i)$ or group of indexed issues and represent it as a function of party membership $(P)$, district interests $(D)$, legislative position $(L P)$, campaign contributions $(C)$, and personal ideology $(I):^{10}$

$$
V_{i}=f_{i}(P, D, L P, C, I)
$$

Since $I$ is inherently unobservable, researchers have typically used a proxy variable-frequently the representative's ADA rating. ${ }^{11}$ ADA is, however, based on a set of votes and hence is a special case of equation (1). Let us represent that set of votes contained in ADA as $V_{A}$; now the typical estimated determinants of the voting equation is

$$
V_{i}=f_{i}\left(P, D, L P, C, f_{A}(P, D, L P, C, I)\right)
$$

The problem with this representation is obvious. Trying to estimate a vote as a function of another vote produces a situation where none of the coefficients obtained is interpretable. This problem is not solved by using the ADA rating from another year, nor by purging the ADA index of certain votes, since membership, district interests, and personal ideology should be fairly stable over time. ${ }^{12}$

If we grant that an incumbent politico cannot be expected to answer ideological questions in any but a strategic manner, and hence a manner that reflects the political constraints that (s)he is

\footnotetext{
${ }^{10}$ Campaign contributions consist of more than money; they include goods, services, and time, all of which are substitutes over some relevant range.

${ }^{11}$ Again, recall how closely related are all the scores of these "ideological" groups (see note 7).

${ }^{12}$ Normally, the use of ADA scores in these studies is modified so as to take out of the votes used in constructing the ADA index those elements that are also part of the votes being explained (so that one is not explaining something by itself). Researchers have in general been careful to take out those votes that they are trying to explain from those that are used by the group in the construction of the ratings. See, for example, Lopreato and Smoller (1978) and Bernstein and Horn (1981). Kau and Rubin (1979a) carry this one step further. They use ADA (residualized) of one year to explain voting in a second year. This practice does nothing to solve the problem we discuss here, unless the following assumption holds: the error terms between years are uncorrelated. We make this assumption explicit.
}

under, there is no independent way to estimate the effect of personal ideology on $V_{i}$. However, if we are willing to accept a "stricter" definition of personal ideology, it is possible to derive an acceptable proxy. To see this, consider the redefined relationship

$$
V_{i}=f_{i}\left(P^{*}, D^{*}, L P^{*}, C^{*}, I^{*}\right)
$$

where $P^{*}$ is now party membership plus that part of the personal ideological structure of the individual representative which is correlated with $P$. $D^{*}$ is the district interests plus that part of $I$ which was correlated with $D ; L P^{*}$ are the constraints from legislative position, plus that part of $I$ which was correlated with $L P ; C^{*}$ is the direct effect of campaign contributions plus the effect of campaign contributions through $I$; and $I^{*}$ is that part of $I$ which was uncorrelated (or orthogonal) with party, legislative position, campaign contributions, and district interests. This new definition of $I^{*}$ can be said to be equivalent to the representative's ideological deviation from those ideological interests of party, legislature, campaign contributions, and district. ${ }^{13}$

That is, to estimate $I^{*}$ we "residualize" ADA. Ignoring $L P$ and $C$ (so as to minimize confusion) for the remainder of this section, let us define a particular linear specification of equation (3) as: ${ }^{14}$

$$
V_{i}=a_{0}+a_{1} P^{*}+a_{2} D^{*}+a_{3} I^{*}+e_{i}
$$

where $e_{i}$ is a pure white noise term distributed with zero mean and a scalar covariance matrix. Now, if we were to estimate this equation without $I^{*}$, we would get

$$
V_{i}=\hat{a}_{\mathrm{o}}^{*}+\hat{a}^{*}{ }_{1} P^{*}+\hat{a}^{*}{ }_{2} D^{*}+\hat{U}_{i}
$$

where $\hat{U}_{i}=\hat{a}_{3} I^{*}+e_{1}$. Note that when $I^{*}$ is omitted $\hat{a}^{*}{ }_{o}$ absorbs the mean value of $I^{*}{ }^{15}$ There is a problem, since $P^{*}$ and $D^{*}$ are unobservable. Equation (5) is, however, equivalent to

$$
V_{i}=\hat{a}^{*}{ }_{\mathrm{o}}+\hat{a}_{1}{ }_{1} P+\hat{a}_{2}{ }_{2} D+\hat{O}_{i}
$$

because of the orthogonality conditions imposed between $I^{*}$ and $P, D$ and $e_{i}$. As Kau and Rubin (1979a) put it, "The coefficients . . . are the same

\footnotetext{
${ }^{13}$ The tie between this notion and that developed by Kau and Rubin (1979a, pp. 368-372) and Johannes and McAdams (1981) should be obvious.

${ }^{14}$ The argument is considerably more complex in detail, but not substance, for many common nonlinear specifications of the equations.

${ }^{15}$ Thus, $I^{*}$ can be redefined as being centered around
} 
as they would have been had ADA not been included"' (p. 370).

Taking the expectation of the observed residual term $\hat{U}_{i}$ in equation (6):

$$
\begin{aligned}
& E(U)=E\left(a_{3} I^{*}+e_{i}\right)=E\left(a_{3} I^{*}\right)+E\left(e_{i}\right) \\
& =E\left(a_{3} I^{*}\right)+E(0)=a_{3} I^{*}
\end{aligned}
$$

Thus, the residuals from equation (6) contain an unbiased estimate of $I^{*}$ scaled by $a_{3} \cdot{ }^{16}$ (Since the scale of $I^{*}$ is unknown, it is of no consequence that $a_{3}$ is unknown.)

Our three newly defined variables have new interpretations, as indicated above. For $a^{*} P^{*}$ and $a_{2}^{*} D^{*}$ incorporate the direct effects of party and the indirect effects of ideology $(I)$ which work through $P$ and $D$ respectively, whereas $a_{3} I^{*}$ represents only the direct effects of personal ideology: independent of $P$ and $D .{ }^{17}$ The reader should be careful to note that since $a_{1}$ and $a_{2}$ are estimates of the direct plus the indirect effects, they are biased estimates of the direct effects. ${ }^{18}$

But there still are problems with using the residuals from equation (6) as a proxy for $I^{*}$. First, even though the expectation of every $e_{i j}$ is zero, it gives us little comfort that this is true on average. There is no reason to believe that the error term associated with any particular representative, in any particular year, will be zero. If we take just one measurement of our residualized ADA, we cannot tell what is being measured: noise or ideology!

We ought to develop a means of estimating the relative magnitude of $I^{*}$ to $e_{i}$ in $\hat{U}_{i}$. To understand this problem, recall that we wish to extract a measure of the representative's personal ideology which we can utilize as an explanatory variable concerning other issues. Imagine that we extract our measure, enter it into a second equation (to explain some other votes), and discover that the coefficients on the residuals from equation (6), suggested here as our proxy for personal ideology, is not significant in the second equation. There are two possible reasons: the residuals from equation (6) did not contain a systematic component (i.e., $I^{*}$ ), or $I^{*}$ was not a determinate of the particular issue. ${ }^{19}$ Now of course it is preferable to be

\footnotetext{
${ }^{16}$ In essence, this is what lay behind the Kau and Rubin (1979a) "residualized" variable, RADA.

"Note the analogy between these interpretations and path analysis.

${ }^{18}$ It is not possible to solve for the coefficients of the direct effects without making assumptions about the covariance between $I, P$, and $D$.

${ }^{19}$ Note that this is a real possibility. Consider, for example, the findings of Chappell (1981a) that ideology did not effect voting on cargo bills.
}

able to identify which of these two things is going on in the data. If one does not do this, it is difficult to identify in which of the issues ideology does play a part. ${ }^{20}$ Thus, our first problem is to find a method to tell us if we have a systematic component in our residuals. To do this, we must discover what is in the residual. We then may be able to use this information to understand better the behavior of representatives. ${ }^{21}$

To sketch the justification of our solutions to these questions, we shall expose the technical roots of our argument. These roots permit identifying the assumptions necessary to justify using the residuals to measure the nonobservable variable. The discussion shall also permit us to interpret our results. ${ }^{22}$

\section{*Matrix Algebraic Analysis of the Approach}

Chamberlain (1977) has developed a sophisticated analysis of the "residualization" method of dealing with unobserved variables in a simultaneous equation framework. His model, "assumes that the common left out variable is the only thing connecting the residuals from these equations, making it possible to extract this common factor and control for it"' (p. 241). Quite clearly, this is our problem. We estimate a restricted version of Chamberlain's "model 1" and develop our technique within his framework (cf. Chamberlain's model 1, 1977, pp. 243-245, 248-250). Here we shall be careful to distinguish between restrictions we make to identify and apply Chamberlain's model and to simplify our presentation. (4):

To begin, consider three variants of equation

$$
\begin{aligned}
& V_{1}=a_{0}+a_{1} P+a_{2} D+a_{3} I+e_{1} \\
& V_{2}=b_{0}+b_{1} P+b_{2} D+b_{3} I+e_{2} \\
& V_{3}=g_{0}+g_{1} P+g_{2} D+g_{3} I+e_{3}
\end{aligned}
$$

${ }^{20} \mathrm{Of}$ course if a significant coefficient is obtained as in most of Kau and Rubin's (1979a) cases, it is safe to assume that the residuals contained $I^{*}$ and that $I^{*}$ was a determinant of the issue being examined.

${ }^{21}$ Assume, for the moment, that we solve this problem. It could still be that in $\hat{O}_{i}, e_{i}$ is very large relative to $I^{*}$. Then, $\hat{U}_{i}$ would be primarily random noise. In such an extreme, a representative may either have no personal ideology or may have one which does not deviate from the ideological interests of party and district. We shall not be able to differentiate well between these two possibilities, in part because of our utilization of a measure of ideology which is "purged" of indirect effects.

${ }^{22}$ Those who are not interested in the technicalities may skip this and other subsection(s) marked with asterisks. 
It will greatly simplify the exposition without affecting the analysis or results if we assume that the constant terms $\left(a_{0}, b_{0}\right.$, and $\left.g_{0}\right)$ and the coefficients of $P\left(a_{1}, b_{1}, g_{1}\right)$, are zero. Now let us write equation (8) in the standard simultaneous equation framework, $T Y=B X+W$. Here,

$$
\left[\begin{array}{lll}
1 & 0 & 0 \\
0 & 1 & 0 \\
0 & 0 & 1
\end{array}\right]\left[\begin{array}{l}
V_{1} \\
V_{2} \\
V_{3}
\end{array}\right]=\left[\begin{array}{ll}
a_{2} & a_{3} \\
b_{2} & b_{3} \\
g_{2} & g_{3}
\end{array}\right]\left[\begin{array}{l}
D \\
I
\end{array}\right]+\left[\begin{array}{l}
e_{1} \\
e_{2} \\
e_{3}
\end{array}\right]
$$

For Chamberlain's model 1 , it is necessary to make restrictions on the $T$ matrix and the error covariance matrix, $W$, which we shall define shortly. ${ }^{23}$ Chamberlain requires $T$ to be upper triangular (or equivalently, lower triangular) and to make enough restrictions on the other elements of $T$ and $W$ to identify the system of equations. Here, we make the most restrictive assumption about $T$, that it is a diagonal matrix (i.e., all of the nondiagonal elements are zero). This is equivalent to saying that the vote on one issue does not affect a vote on another issue and implies that a vote on an issue does not affect district interests or personal ideology. These restrictions are unnecessary and they are testable. ${ }^{24}$

Next, we turn to the $B$ matrix and the $X$ vector. Note again, $I$ is not observable. ${ }^{2 s}$ Rewriting equation (9) to take I's nonobservable nature into account we have:

$$
\begin{aligned}
& {\left[\begin{array}{lll}
1 & 0 & 0 \\
0 & 1 & 0 \\
0 & 0 & 1
\end{array}\right]\left[\begin{array}{l}
V_{1} \\
V_{2} \\
V_{3}
\end{array}\right]=} \\
& {\left[\begin{array}{l}
a_{2} \\
b_{2} \\
g_{2}
\end{array}\right][D]+\left[\begin{array}{l}
a_{3} \\
b_{3} \\
g_{3}
\end{array}\right][I]+\left[\begin{array}{l}
e_{1} \\
e_{2} \\
e_{3}
\end{array}\right]}
\end{aligned}
$$

As noted earlier, however, this is equivalent to

\footnotetext{
${ }^{23}$ Chamberlain's other models are developed for cases where alternative types of assumptions might be more appropriate. His model 2 requires restrictions on $B$ and $W$. His model 3 requires restrictions on $T$ and $B$ as well as $\dot{W}$.

${ }^{24}$ One could utilize a simultaneous equation model, similar to those of Kau, Keenan, and Rubin (1982) and Chappell (1981a) to test these assumptions, within our framework. We shall not do this here, however.

${ }^{25} I=I^{1}+I^{*}$ where the orthogonal decomposition desired is such that $\operatorname{cov}\left(I^{1}, D\right) \neq 0$ and $\operatorname{cov}\left(I^{*}, D\right)=0$. Either $I^{1}$ or $I^{*}$ or both may be zero vectors. We make the further standard assumption that $I$ is nonstochastic and hence uncorrelated with the stochastic error terms $e_{1}, e_{2}$, and $e_{3}$.
}

$$
\begin{aligned}
& {\left[\begin{array}{l}
a_{2} \\
b_{2} \\
g_{2}
\end{array}\right][D]+\left[\begin{array}{l}
U_{1} \\
U_{2} \\
U_{3}
\end{array}\right]} \\
& \text { where } U=\left[\begin{array}{l}
a_{3} \\
b_{3} \\
g_{3}
\end{array}\right]\left[I^{*}\right]+\left[\begin{array}{l}
e_{1} \\
e_{2} \\
e_{3}
\end{array}\right]
\end{aligned}
$$

and $\hat{a}_{2}^{*}, b^{*}, \hat{g}_{2}^{*}$ are the estimated coefficients which would exist if $D^{*}$ were the only independent variable. ${ }^{26}$ The formulas given by Chamberlain $\left(1977\right.$, p. 245) may be used to solve for $a_{3}, b_{3}$, and $g_{3}$. In our case, we are only interested in one coefficient for $I^{*}$, say $g_{3}$. With the restriction we have imposed on the $T$ and $W$ matrices, we no longer have a truly simultaneous equation system, although it does no harm to estimate it as one.

\section{Stage 1. Obtaining $I^{*}$ from the Residuals to Apply to a Second Stage}

A shortcut allows us to answer the questions we posed earlier about using the residuals as an estimator for I*: "What is in the residuals?" If two or more equations are available, a simple test of the relative magnitudes of the variance of the random error terms is available. ${ }^{27}$ To see this, we must first estimate the equations and obtain the residuals, $\hat{U}_{i}$. Do this for two equations so that $\hat{U}_{1}$ $=\hat{a}_{3} I^{*}+e_{1}$ and $\hat{U}_{2}=b_{3} I^{*}+e_{2}$.

What happens if. we calculate the correlation coefficient between $\hat{U}_{1}$ and $\hat{U}_{2}{ }^{{ }^{28}}$ At the extremes, obviously if $r=0, I^{*}$ is a constant (and hence does not explain differences in voting patterns), and if $r=1, e_{1}$ and $e_{2}$ have zero variances, and the observed residuals are composed of only $I *{ }^{29}$ How large $r$ must be in order for the residuals to

${ }^{26}$ Recall that $D^{*}=\left(D+I^{1}\right)$. Note also that equation (11) is now estimatable as a system of Zellner seemingly unrelated regression equations, and no additional restrictions (given our $T$ ) are needed. It makes our situation much easier, however, if we restrict the covariances of $e_{1} e_{2}, e_{1} e_{3}$, and $e_{2} e_{3}$ to be zero. Given these assumptions, the expectation of error covariance matrix can be calculated, as can the coefficients of $I^{*}$ when regressed against ADA.

${ }^{27}$ This test depends on our assumption that the error terms are not correlated across equations (see note 12). $\hat{U}_{1}$ and $\hat{U}_{2}$ may be seen as instrumental variables for $I^{*}$.

${ }^{28}$ Note that if there are more than two equations, it is possible to add the residuals together and average them first in order to perform the test.

${ }^{29}$ This approach also could be applied to calculate the correlation of the coefficients of $I^{*}$ in the observed residuals (if they were to be used as an independent variable in a second stage of a multi-stage model) and also to an estimate of the ratio of $a_{3}$ to $b_{3}$. 
be a useful proxy is a decision for the individual researcher..$^{30}$

Now we have two different residuals, each of which contains $I^{*}$. How do we maximize the validity of our measure? If we average these residuals, we get $1 / 2 .\left(a_{3}+b_{3}\right) I^{*}+e_{1}+e_{2}$, and this average minimizes the effects of a large (or peculiar) outlier in any one observation (see Chamberlain, 1977, pp. 249-250). If we had a large number of equations from which to take the observed residuals, it would be reasonable to assume that the sum of the error terms would be zero for all representatives. This is analogous to the test-retest concept familiar in the psychological literature where the observed test score is equal to the true test score plus a random error term that cancels out in repeated testing. Thus, the more equations from which the residuals are obtained, the more reasonable the assumption that the error sum equals zero. We shall later measure the personal ideological variable (over the decade of the 1970s) and, assuming it to remain stable, utilize an averaging process to get a measure which minimizes the effects of single outliers and increases the likelihood of the error terms as summing to zero for all observations.

\section{Summary of Stage 1}

Thus, we can again summarize the assumptions that are required for this approach to make sense:

1. "The common left-out variable is the only thing connecting the residuals from these equations, making it possible to extract this common factor and control for it." (p. 241, Chamberlain). ${ }^{31}$

2. $T$ is upper triangular (or, equivalently, lower triangular), and $T$ and $W$ are restricted enough to identify the system of equations.

Here, we made the most restrictive assumption about $T$ : that it is a diagonal matrix (i.e., all of the nondiagonal elements are zero). This is

\footnotetext{
${ }^{30}$ In our discussion above, regarding $r$, we implicitly assumed that $a_{3}$ and $b_{3}$ were nonzero and that their sum was nonzero. The necessity of making these assumptions suggests that we need two or more equations where the absolute values of $a_{3}$ and $b_{3}$ are as large as possible, relative to their standard errors, and that it is better if $a_{3}$ and $b_{3}$ be of the same sign so there is no chance of their cancelling out.

"Of course, any variable which is not explicitly entered into the equations to explain ADA could account for the statistical results we report here. It is our belief that any critic's suggestion that the residual really represents another variable must be taken seriously. It is also our belief that the burden of proof is the critic's.
}

equivalent to saying that a vote on one issue does not affect a vote on another issue and implies that a vote on an issue does not affect district interests or personal ideology.

Now how are we to proceed? We wanted to estimate $I$, an unobservable. The best we can do is to estimate $I^{*}$, which is the ideological variable, stripped of its "indirect" effects. To find $I^{*}$ we residualize $A D A$. Beyond this, we must estimate the relative contents of the residual term: How much is noise and how much is $I^{*}$ ? To do this we: First, choose two or more equations where the absolute values of $a_{3}$ and $b_{3}$ are likely to be large. The most likely candidates are those equations where $V_{i}$ is an ideological vote or group of votes. Second, we choose two or more equations with similar dependent and independent variables. If most variables are stable over time, estimating the same equation in two or more different time periods immediately suggests itself. We will shortly utilize both of these criteria in developing our research design to probe $I^{*}$, but we first summarize the procedure.

1. Take two or more iterations of the same theoretical model such that $I$ is the only unobserved variable.

2. Perform $r$, or $\bar{R}^{2}$, test to identify the relative magnitude of the variance that one can ascribe to $I^{*}$ and to the random error terms.

3. Obtain the observed residuals from these equations and average them.

4. Use the average of the observed residuals as a measure of $I^{*}$ in stage 2 .

In what follows, it is important to recall a few important points made earlier. I*.

The constant term absorbs the mean value of

The coefficients of other independent variables are the unbiased estimates of the direct effects plus the indirect effects of $I$, but are biased estimators of the direct effects. Therefore, the estimated variances of the coefficients are positively biased estimates of the true variance of the direct plus indirect effects of $I$, which implies that the $t$-test is more conservative than the indicated level of significance. The estimated variances of the coefficients are biased (in an unknown direction) estimates of the true variance of the direct effect coefficients.

If $I^{*}$ has a significant coefficient, then personal ideology has an effect. The opposite result is more difficult to interpret since it may occur because $I$ has no direct effect after being purged of its correlation with other included variables. Hence our test is extremely strict and will have a low power in rejecting the null hypothesis (i.e., that personal 
ideology is not a determinant of voting on a particular issue).

\section{An Illustrative Application of the Residualization Technique}

Let us apply our method for the extraction of a measure of the direct effects of personal ideology, $I^{*}$. To identify $I^{*}$ we select a set of votes and identify what is left unexplained by the legislator's party, district, and legislative position. Using ADA votes as a simple indicator for overall manifest ideology, we "explain" those votes by a set of political constraints and personal political values. Consider a simple expansion of our linear specification of the model (equation 3) above $\mathrm{e}^{32}$

$$
\begin{gathered}
A D A=B_{0}+B^{*}{ }_{1} P^{*}+B^{*}{ }_{2} D^{*} \\
+B^{*} L P^{*}+\left(B_{4} I^{*}+e_{1}\right)
\end{gathered}
$$

If our hypothesis is correct, the observed residual term (in the brackets) contains personal ideology as well as a random error term. As indicated above, that term does not readily permit interpretation because it does not provide a means of separating out the two components and because the error term can not be expected to be zero for any single observation. So now let us specify the same equation for two different (perhaps multiyear) time periods (see equations $13 \mathrm{a}$ and $\mathrm{b}), t$ and $t-1 . .^{33}$

\footnotetext{
${ }^{32}$ Note that we have dropped campaign contributions from our specification of equation (12), owing to the unavailability of detailed campaign contribution data necessary for much of the time period covered by the data we utilize in the next sections. For later years it is available (see Kau et al., 1982, for a sophisticated treatment of 1979 votes and 1978 campaign contributions by groups). Our omission of campaign contributions is mitigated to some extent by the large number of district characteristics we include in our empirical specification. To the extent that campaign contributions are proportional to the strength of included variables, their effects will be absorbed by those coefficients. We would hypothesize two routes for the effects of campaign contributions on ideology: first, a general indirect "purchase" of ideology and second, a general "purchase" of particular votes. The first route is testable by calculating the correlation coefficient between our estimated measure of ideology and contributions, and the second route by entering contributions directly as an independent variable in a regression on the determinants of those votes. Not surprisingly, preliminary research with campaign contributions from later years indicates the second route to be much more important than the first.
}

${ }^{33}$ In practice, two-year periods are congressional sessions and represent the longest time period that the researcher can be assured of the same representatives
Our measure, $I^{*}$, can now be developed as follows. We have two equations where $I^{*}$ appears in the residual term. From equation (12) and the above discussion, consider the following equations:

$$
\begin{aligned}
& A D A_{t}=A_{0}+A_{1} P^{*}+A_{2} D^{*}+A_{3} L P^{*} \\
& \quad+\left(A_{4} I^{*}+e_{t}\right) \\
& A D A_{t-1}=B_{0}+B_{1} P^{*}+B_{2} D^{*}+B_{3} L P^{*} \\
& \quad+\left(B_{4} I^{*}+e_{t-1}\right)
\end{aligned}
$$

where $t$ and $t-1$ will represent even and odd years respectively for our purposes. This is a recursive simultaneous equation system which can be estimated with OLS or GLS, as appropriate. ${ }^{34}$

$I^{*}$ can now be consistently estimated by regressing $\left(A_{4} I^{*}+e_{t}\right)$ on $\left(B_{4} I^{*}+e_{t-1}\right)$ which becomes:

$$
B_{4} I_{2}^{*}=C_{1}\left(A_{4} I_{1}^{*}+e_{t-1}\right)+e_{t}
$$

or alternatively:

$$
A_{4} I^{*}=C_{2}\left(B_{4} I_{2}^{*}+e_{t}\right)-e_{t-1}
$$
$I^{*}:$

Note that we have now defined two measures of

$$
\hat{I}_{2}^{*}=\left(\hat{C}_{1} / B_{4}\right)\left(A_{4} I^{*}{ }_{1}+e_{t-1}\right)
$$

and

$$
\hat{I}_{1}^{*}=\left(\hat{C}_{2} / A_{4}\right)\left(B_{4} I_{2}^{*}+e_{t}\right)
$$

both of which are consistent estimators of $I^{*}$. Since we have no knowledge of which one is the most efficient consistent estimator of $I^{*}$, we minimize the risk of a wrong choice and allow for counterbalancing error terms by averaging $\hat{I}^{*}{ }_{1}$ and $\hat{I}_{2}^{*}$ :

$$
\hat{I}^{*}=\left(\hat{I}_{1}^{*}+\hat{I}_{2}^{*}\right) / 2 \text {. }
$$

Now let us turn to an empirical estimation of the model we proposed above. Estimation of voting models requires the use of qualitative

serving together. If the coefficients across different congressional sessions are assumed to be stable, different sessions may be "stacked," exploiting the large number of degrees of freedom. We have made this assumption; it is not necessary.

${ }^{34}$ Although we have assumed the independent variables in both equations to be the same, this is not necessary for our argument. Indeed, one could imagine that in the United States the functional relationship would be different even (election) years and odd (off) years. 
limited dependent variable techniques, maximum likelihood probit or logit for single votes and for voting indices, generalized least squares (GLS) with a probit or logit transformation of the dependent variable to correct for known statistical problems with ordinary least squares regression model (Hanushek \& Jackson, 1977). We have used the GLS probit (Judge et al., 1980, 1982) because of the desirability of probit's normal error term assumption. ${ }^{35}$ The necessary GLS weights, however, create a problem that has not been dealt with earlier: the unweighted residuals from equations (13a) and (13b) need not have a zero mean and may be correlated with the independent variables in those equations. We need to insure the zero mean and the lack of correlation between $I^{*}$ and the original set of independent variables so as to allow future weighting of these variables (via probit, etc.) to be interpretable; that is, the unweighted form (rather than the form generated after a probit transform and weights) of the residualized variables must be uncorrelated with the other independent variables. Thus, to use $I^{*}$ in equation (16), it is necessary to regress the unweighted residuals of equations (13a) and (13b) against the unweighted independent variables in those equations. (Table 1 reports the regression equations for equations (13a) and (13b).) One can then use the resulting residuals as the measures in equations (15a) and (15b). ${ }^{36}$

Tables 1, 2, and 3 report the results of an application of the proposed technique to the measurement of the ideology of U.S. senators during the 1970s. In Table 1 we have regressed many state characteristics against each senator's annual ADA rating, to identify the residual. (This is in direct contrast with Johannes and McAdams, 1981, p. 517, who regress ADA only with the 1972 McGovern vote.) Personal ideology, by hypothesis, is in this residual. In this procedure we have taken what could be described as a kitchen-sink approach to estimating the ADA equation. In general this is an unacceptable practice because the multicollinearity can be so high that little or nothing can be said about the influence and significance of any of the coefficients. However, our purpose here is simply to minimize the sum of squares of the residuals and to guard against leav-

\footnotetext{
${ }^{35}$ The choice between probit and logit is, however, arbitrary for most applications. In either case it is necessary to use a correction factor to prevent exact zeros and ones which are undefined. We used the one suggested by Lindgren and McElrath (1969).

${ }^{36}$ The result of these two auxiliary regressions are not reported here but are available from the authors. The correlation between the two versions of the residuals is approximately .9 for even, and .8 for odd, years.
}

ing out any significant systematic factors which would otherwise become a part of our estimated $I^{*}{ }^{37}$ Therefore, in this case, no harm is done by this eclectic approach.

We ask the reader to forgive us: we feel that we must indulge ourselves with an interpretation of the above results which has nothing to do with the main thrust of this article. Consider the coefficients on the DELECT and RELECT variables. They appear to be indicating something quite important. It appears, from their sign and size and significance that we can conclude that first, pressures for reelection affect primarily voting in the odd calendar years. Thus it appears that the incumbent campaigns on his previous year's record. Further, and this is of some theoretical importance, the Democrats are pushed to the right, and the Republicans to the left, by the elections. If you wish, during odd years they seem to converge (toward some median voter?) whereas during even years (when their votes are perhaps too close in time to be fully digested and considered by the interested public for the election), the parties are further apart and driven more by their natural coalition members. This observation would indicate that any model of party behavior should combine the median voter analysis of Downs along with the coalitional analysis of those cited in note 4 above.

The above regressions leave residuals that (after correcting for the GLS weights), we conjecture to be personal ideology. If our conjecture is correct, these residuals should be related, and we can check the validity of our measure by regressing the residuals of the odd years against the residuals of the even years. Doing this would lead us to expect a sizable correlation between the two sets of years (the larger the correlation, the more stable, and the larger the $I^{*}$ component in the residuals). ${ }^{38} \mathrm{We}$ report this test in Table 2. These results show that the observed unweighted, corrected, residuals share a common variance of $36 \%$ of their variance.

Yet another test suggests itself, if $B_{4} I^{*}{ }_{1}=0$, or the average of the two residuals (i.e., if people have no personal ideology as measured or if $I^{*}$

\footnotetext{
"One could emphasize further the coalitional aspects of the relationship between constituents and voting in the legislature. To do this, one could enter each of the district characteristics twice: once modified by a dummy variable representing party. Such a model would perhaps better represent the works indicated in note 4 above.

${ }^{38}$ The formula for the correlation coefficient clearly shows what is happening, given our assumptions:

$r=\left(\operatorname{var}\left(I^{*}\right) /\left\{\operatorname{var}\left(I^{*}\right)+\left[\operatorname{var}\left(e_{1}\right)\right]^{1 / 2}+\left[\operatorname{var}\left(e_{2}\right)\right]^{1 / 2}\right\}\right.$
} 
Table 1. Estimation of Personal Ideology (U.S. Senate, 1970-1980)

\begin{tabular}{|c|c|c|c|c|}
\hline \multirow[b]{3}{*}{ Independent variables ${ }^{a}$} & \multicolumn{4}{|c|}{ Dependent variable } \\
\hline & \multicolumn{2}{|c|}{$\mathrm{ADA}^{\mathrm{b}}$ (even years) } & \multicolumn{2}{|c|}{$\mathrm{ADA}^{\mathrm{b}}$ (odd years) } \\
\hline & Coefficient & $t$-Statistic & Coefficient & $t$-Statistic \\
\hline Intercept & -0.029 & -0.0 & -2.091 & -0.8 \\
\hline Party & 0.724 & 9.7 & 0.802 & 9.4 \\
\hline New England & 0.157 & 0.7 & -0.392 & -1.7 \\
\hline East North Central & 0.028 & 0.2 & 0.601 & 4.1 \\
\hline West North Central & -0.708 & -4.7 & -0.130 & -0.8 \\
\hline South Atlantic & -0.759 & -4.3 & -0.695 & -3.6 \\
\hline East South Central & -0.534 & -2.1 & -0.646 & -2.2 \\
\hline West South Central & -0.744 & -3.2 & -0.163 & -0.7 \\
\hline Mountain & -0.932 & -4.5 & -0.244 & -1.1 \\
\hline Pacific & -0.511 & -2.5 & -0.486 & -2.2 \\
\hline DElect & -0.086 & -1.7 & -0.143 & -2.7 \\
\hline RElect & 0.031 & 0.3 & 0.424 & 4.1 \\
\hline PMcGov & 0.029 & 4.5 & 0.035 & 5.2 \\
\hline PCarter & 0.028 & 3.3 & 0.009 & 1.0 \\
\hline SREP & 0.107 & 0.7 & 0.142 & 0.8 \\
\hline PAFLCIO & 0.013 & 1.6 & -0.019 & -2.1 \\
\hline PMAN & -0.072 & -4.8 & 0.039 & 2.5 \\
\hline YOFF & -0.002 & -0.5 & -0.007 & -1.8 \\
\hline PBLACK & 0.008 & 1.1 & -0.007 & -0.9 \\
\hline MVAGE & 0.029 & 1.1 & 0.094 & 3.5 \\
\hline MFINC & -0.000 & -0.7 & 0.000 & 2.2 \\
\hline MEDUC & 0.512 & 3.7 & -0.032 & -0.2 \\
\hline PWC & -0.034 & -1.5 & -0.035 & -1.3 \\
\hline PSERV & 0.250 & 6.7 & -0.136 & -3.6 \\
\hline PFARM & 0.004 & -0.2 & -0.028 & 1.6 \\
\hline PCC & -0.007 & -1.7 & 0.000 & 0.0 \\
\hline PSUB & 0.015 & 3.9 & 0.002 & 0.6 \\
\hline PFEDS & 0.000 & 2.9 & 0.000 & 1.5 \\
\hline PCOIL & -3.659 & -3.3 & -2.594 & 2.0 \\
\hline PCNGAS & 0.229 & 1.3 & -0.123 & -0.7 \\
\hline PCCOAL & 2.682 & 0.2 & -4.452 & -1.3 \\
\hline PENGROUP & 0.924 & 6.0 & 0.521 & 3.4 \\
\hline \multirow[t]{2}{*}{ PCCAUSE } & -5.120 & -3.7 & 0.205 & -0.1 \\
\hline & \multicolumn{2}{|c|}{$R^{2}=.57$} & \multicolumn{2}{|c|}{$R^{2}=.54$} \\
\hline
\end{tabular}

a Some of the variables are self-evident; those that aren't are: a dummy variable indicating the year a Democrat (Republican) faces reelection: DElect (RElect); SREP: a dummy variable indicating a southern Republican; the percent of the vote for McGovern and Carter (1976): PMcGov, PCarter; percent of the labor force in the AFL-CIO: PAFLCIO; the percent of the labor force in manufacturing: PMAN and farming: PFARM; the incumbent's years in office: YOFF; the median voter's age in the district: MVAGE; median family income: MFINC; median education: MEDUC; percent white collar: PWC; and percent service worker in the labor force: PSERV; percentage of the federal budget received by the state; PFED; the percentage of the state population belonging to 7 national environmental groups: PENGRP; the percent of the population belonging to Common Cause: PCCAUSE; the production of oil, natural gas, and coal: PCOIL, PCNGAS, \& PCCOAL respectfully. All of the data are taken from Barone, et al., Almanac of American Politics, 1970-1982, except (1) the figures on the membership in the interest groups (Common Cause, the environmental groups, and the AFL-CIO) which were obtained directly from the groups involved and (2) the energy production figures which came from Shreck (1977), pp. 940, 1081, and 397.

bHere the actual dependent variable is the PROBIT transformation of the ADA evaluation. See note 35. 
Table 2. Regressing the Odd Years and the Even Years Residuals

\begin{tabular}{|c|c|c|c|c|c|}
\hline \multicolumn{3}{|c|}{$\begin{array}{l}\text { Dependent variable } e_{t}+B_{4} I_{2}^{*}= \\
\text { Unweighted even year residuals }\end{array}$} & \multicolumn{3}{|c|}{$\begin{array}{l}\text { Dependent variable } e_{t}+A_{4} I_{1}^{*}= \\
\text { Unweighted odd year residuals }\end{array}$} \\
\hline $\begin{array}{l}\text { Independent } \\
\text { variable }\end{array}$ & Coefficient & $t$-Statistic & $\begin{array}{l}\text { Independent } \\
\text { variable }\end{array}$ & Coefficient & $t$-Statistic \\
\hline Intercept & $5.55 \times E-14$ & 0.0 & Intercept & $-4.44 \times E-14$ & 0.0 \\
\hline$e_{t}+A_{4} I_{1}$ & .567 & 16.6 & $e_{t}+B_{4} I_{1}$ & .642 & 16.6 \\
\hline \multicolumn{6}{|c|}{$n=483$} \\
\hline \multicolumn{6}{|c|}{$\bar{R}^{2}=.36$} \\
\hline
\end{tabular}

plays no role in determining ADA), then adding the observed residual to the equation for the $t-1$ time period as an independent variable should not greatly effect the explanatory power of the equation. After all, adding the residual would merely be adding a random error term. On the other hand, if it does contain personal ideology, then it will significantly increase the overall explanatory power of the time period $t$ regression.

Performing this test supports our conjecture. We considered the set of senators and their ADA ratings in even and odd years. ${ }^{39}$ We found that we could explain $54 \%\left(R^{2}\right)$ of the variance of ADA in odd years using $D, L P$, and $P$, and $64 \%\left(R^{2}\right)$ of the variance when augmenting those variables with the even years' residuals. Similarly, in even years, the figures are $57 \%$ and $68 \%$, for gains in both data sets of a bit more than $10 \%$.

With these strong results, we continue with our investigation. Are the residuals a sensible indicator of the senators' ideologies? To see this we transform the residuals onto a scale from -1 (conservative) to +1 (liberal). These techniques are utilized to calculate $I^{*}$ for members of the Senate in 1979 and 1980, and the results are reported in the next table (Table 3). Although here we perform no statistical checks on these results, one is able to ask whether the results are intuitively plausible.

Our intuition is not fully satisfied with these results. A close examination shows, for example, there are a number of peculiar rankings that must be mentioned. But first, note that we are not accustomed to think of the representative's ideology in this fashion, and hence there are bound to be some seemingly anomalous results. The causes for these anomalies should perhaps be discussed. Putting this aside as nontrivial, and yet not quite to the point, other obvious causes for anomalies

\footnotetext{
${ }^{39} \mathrm{By}$ beginning with an odd year, the ADA rating is not affected by the defeat of an incumbent in an election during the period examined.
}

come to mind. First, unlike the results given at other points in this article, the scores are calculated only over a two-year period. Hence all the vagaries of small numbers of observations for each person come into play. Consider the case of Williams (D, N.J.) for example. His ADA ratings in 1979 and 1980 were uncharacteristically low. For the years from 1972 to 1978 , he averaged an $86 \mathrm{ADA}$, and had no score below 80 . His average would have yielded him a $I^{*}$ of about -.46 (note, still in the most conservative quartile). Second, as indicated at various points above, there is no attempt to take into account the specifically coalitional constraints upon the representatives; that is, we have not tried to develop a model that takes into account the specific local array of interest groups supporting each of the senators. The only time we even approximated this, by considering southern Republicans as separate from other Republicans, we found that they tended to differ from other Republicans. Southern Republicanism was tied (weakly, to be sure) to a more liberal record. Presumably, some of the variance would be explained by such a variable. Finally, there has been no attempt to introduce the financial constituents, or backers, of the representatives, as a further constraint to their voting behavior. Were we to follow up on these last two points, the ratings could change quite substantially. But there would still be an unexplained pattern to the anomalies: southern Democrats who were not very conservative now appear, by our measure, to be quite liberal. (See, for example, Hollings of South Carolina.) On the other hand, liberal Republicans are given quite a boost for their bucking of the (negative) ideological correlation between Republicanism and the ADA. For examples, note Leahy of Vermont and Weicker of Connecticut. By permitting a coalitional variable to be included, some of the anomalous weightings for nonconservative southern Democrats and liberal northern Republicans could well be mitigated, but probably not all. Recall that we are not used to thinking about ideology this way, partially 
Table 3. Ideological Scores: U.S. Senators, 1979-1980a

\begin{tabular}{|c|c|c|c|c|c|c|c|c|c|}
\hline \multirow[b]{2}{*}{ State } & \multirow[b]{2}{*}{ Senator } & \multirow[b]{2}{*}{$\mathrm{I}^{* \mathrm{~b}}$} & \multicolumn{2}{|c|}{ ADA } & \multirow[b]{2}{*}{ State } & \multirow[b]{2}{*}{ Senator } & \multirow[b]{2}{*}{$I^{* b}$} & \multicolumn{2}{|c|}{ ADA } \\
\hline & & & 1980 & 1979 & & & & 1980 & 1979 \\
\hline N.J. & *Bradley & -1.03 & 72 & 68 & N.C. & *Morgan & -0.00 & 22 & 26 \\
\hline Vt. & *Stafford & -1.01 & 61 & 47 & Colo. & $*_{\text {Hart }}$ & 0.01 & 61 & 58 \\
\hline N.Y. & *Moynihan & -0.89 & 72 & 47 & Ohio & *Metzenbaum & 0.02 & 83 & 84 \\
\hline Pa. & Schweiker & -0.89 & 17 & 16 & Ill. & Percy & 0.02 & 39 & 47 \\
\hline N.J. & *Williams & -0.82 & 72 & 74 & W. Va. & *Randolph & 0.04 & 72 & 32 \\
\hline Iowa & Jepsen & -0.80 & 22 & 0 & Kans. & Dole & 0.04 & 22 & 21 \\
\hline Conn. & $*$ Ribicoff & -0.75 & 56 & 53 & Hawaii & *Inouye & 0.05 & 67 & 37 \\
\hline Nebr. & *Zorninsky & -0.66 & 22 & 21 & N.M. & Domenici & 0.08 & 17 & 5 \\
\hline Mass. & *Tsongas & -0.64 & 89 & 74 & Nev. & Laxalt & 0.08 & 11 & 5 \\
\hline Minn. & Boschwitz & -0.63 & 28 & 21 & W. Va. & *Byrd & 0.09 & 56 & 53 \\
\hline IIl. & *Stevenson & -0.60 & 61 & 68 & Miss. & *Reigle & 0.11 & 83 & 84 \\
\hline N.D. & Young & -0.58 & 11 & 5 & Ala. & *Helfin & 0.12 & 39 & 26 \\
\hline Alaska & *Grave1 & -0.56 & 39 & 47 & N.C. & Helms & 0.12 & 11 & 5 \\
\hline Calif. & Hayakawa & -0.54 & 22 & 11 & Calif. & ${ }^{*}$ Cranston & 0.13 & 83 & 79 \\
\hline Wis. & *Proxmire & -0.51 & 56 & 42 & Tex. & *Bentsen & 0.14 & 39 & 26 \\
\hline Ohio & *Glenn & -0.46 & 67 & 53 & Md. & *Sarbanes & 0.15 & 83 & 79 \\
\hline Nebr. & *Exon & -0.46 & 39 & 21 & N.D. & *Burdick & 0.16 & 78 & 63 \\
\hline Mont. & *Melcher & -0.44 & 50 & 58 & Hawaii & *Matsunaga & 0.16 & 78 & 53 \\
\hline Wash. & *Magnuson & -0.42 & 72 & 53 & Mich. & ${ }^{*}$ Levin & 0.17 & 94 & 74 \\
\hline Ariz. & Goldwater & -0.40 & 0 & 5 & Fla. & *Chiles & 0.18 & 50 & 42 \\
\hline Okla. & *Boren & -0.40 & 28 & 16 & Tex. & Tower & 0.20 & 6 & 11 \\
\hline N.H. & Humphrey & -0.37 & 6 & 5 & N.Y. & Javits & 0.20 & 61 & 63 \\
\hline Idaho & McClure & -0.32 & 17 & 0 & Oreg. & Hatfield & 0.22 & 50 & 58 \\
\hline R.I. & *Pell & -0.32 & 78 & 68 & Alaska & Stevens & 0.22 & 39 & 21 \\
\hline N.H. & *Durkin & -0.27 & 50 & 37 & Utah & Garn & 0.25 & 17 & 11 \\
\hline Nev. & *Cannon & -0.25 & 33 & 21 & Okla. & Bellmon & 0.26 & 28 & 16 \\
\hline Idaho & ${ }^{*}$ Church & -0.24 & 50 & 42 & S.D. & *McGovern & 0.27 & 56 & 100 \\
\hline Fla. & *Stone & -0.23 & 33 & 21 & N. Mex. & Schmitt & 0.28 & 17 & 16 \\
\hline Ind. & Lugar & -0.22 & 17 & 11 & Tenn. & Baker & 0.28 & 17 & 21 \\
\hline S.D. & Pressler & -0.22 & 17 & 32 & Ky. & *Ford & 0.28 & 78 & 32 \\
\hline Del. & Roth & -0.20 & 22 & 21 & Tenn. & *Sasser & 0.29 & 67 & 37 \\
\hline Ky. & *Huddleston & -0.17 & 44 & 37 & Mo. & *Eagleton & 0.30 & 78 & 58 \\
\hline Wash. & *Jackson & -0.17 & 72 & 68 & Utah & Hatch & 0.30 & 17 & 11 \\
\hline Colo. & Armstrong & -0.15 & 17 & 11 & Wyo. & Simpson & 0.32 & 17 & 11 \\
\hline Ga. & *Talmadge & -0.15 & 33 & 16 & R.I. & Chaffee & 0.39 & 72 & 47 \\
\hline Ariz. & *Deconcini & -0.13 & 67 & 26 & Ark. & *Bumpers & 0.40 & 56 & 53 \\
\hline Mont. & *Baucus & -0.13 & 72 & 63 & Mo. & Danforth & 0.40 & 50 & 16 \\
\hline La. & *Johnston & -0.13 & 33 & 16 & Wyo. & Wallop & 0.41 & 22 & 11 \\
\hline Oreg. & Packwood & -0.10 & 56 & 32 & Miss. & *Stennis & 0.42 & 17 & 11 \\
\hline Maine & Cohen & -0.09 & 33 & 42 & Wis. & *Nelson & 0.43 & 89 & 84 \\
\hline Va. & Warner & -0.08 & 22 & 5 & Md. & Mathias & 0.51 & 72 & 63 \\
\hline Ind. & *Bayh & $-0,06$ & 61 & 63 & Kans. & Kassenbaum & 0.53 & 44 & 37 \\
\hline Minn. & Durenberger & -0.05 & 44 & 53 & S.C. & Thurmond & 0.59 & 17 & 5 \\
\hline Ga. & *Nunn & -0.04 & 56 & 11 & S.C. & *Hollings & 0.64 & 39 & 32 \\
\hline Iowa & *Culver & -0.03 & 78 & 74 & Ala. & *Stewart & 0.67 & 61 & 42 \\
\hline $\mathrm{Pa}$. & Heinz & -0.03 & 50 & 42 & Conn. & Weicker & 0.71 & 72 & 68 \\
\hline Del. & *Biden & -0.03 & 67 & 53 & Vt. & Leahy & 0.89 & 83 & 89 \\
\hline Ariz. & *Pryor & -0.01 & 44 & 42 & Miss. & Cochran & 0.89 & 22 & 5 \\
\hline La. & *Long & -0.00 & 28 & 11 & & & & & \\
\hline
\end{tabular}

*Democrat.

${ }^{a}$ Kennedy (Mass.) was omitted owing to excessive absence resulting from campaign activities, Muskie (Maine) because he resigned to become Secretary of State, and Byrd (Va.) because he is an independent.

bThe larger the score, the more liberal the ideology. Note that in these "normalized" scores, we have centered the scores around zero (by subtracting the mean). The scores reflect the average for the two years. 
Figure 1. The Current Paradigmatic Model to Explain

Voting Patterns of Legislators

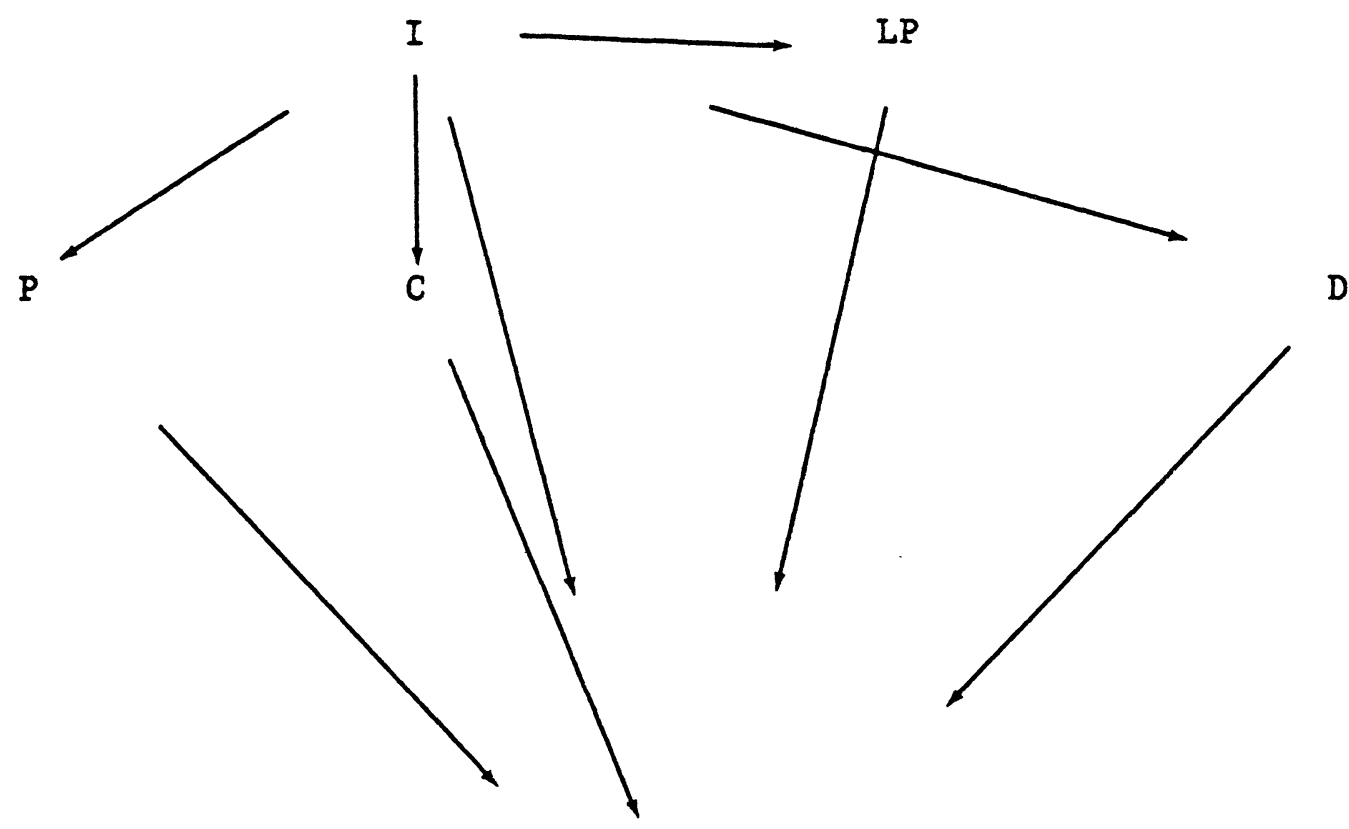

because $I^{*}$ is that segment of ideology which is independent of party. A reexamination of Table 1 helps to illuminate the issue. Not surprisingly, party and region are extremely important constraints of ADA. Hence bucking these political constraints yields large residuals or $I^{*}$. Typically, then, our measure puts strong liberal labels on Republicans who are liberal, and southerners who are not extreme conservatives. Conservative labels go to Democrats who are less liberal than their party-region nexus might lead one to believe. Hence, Leahy, the Vermont Republican, has very little pressure to vote liberal. Both his party and his state push him to the right. An ADA score of 83 reveals him as a great liberal bucking these constraints. Williams, on the other hand, is from a state with demographic, political, and economic characteristics which push him to the left, and he is a Democrat. Thus, his ADA scores in the 70s disappoint a liberal's statistical expectation, and he is labelled a conservative. ${ }^{40}$

${ }^{40}$ Note that the (earlier) very liberal record of the Republican, Case, from the same state, merely reinforces this impression.
Another aspect of our measure of ideology also of interest is its correlation with other standard voting indices. These correlations are: .475 with ADA; .343 with the League of Conservation Voters score; and .327 with COPE.

\section{Stage 2: Explaining Observed Legislative Voting Patterns}

Recall the problem: we wish to explain a subset (other than ADA) of the $i^{\text {th }}$ iegislator's voting record. The general paradigm for the analysis of legislative voting is illustrated in Figure 1. There, party $(P)$, ideology $(I)$, legislative position $(L P)$, campaign contributions $(C)$, and district characteristics $(D)$ are seen as together determining legislative voting patterns. A subset of these votes (call it $S$ ) is of interest to us. More specifically, note that $V_{i}$ can be thought of as follows:

\footnotetext{
$V_{i}=Y_{j} / n(j=1 \ldots n)$ (where $Y_{j}=1$ for a yes/ positive single vote and $Y_{j}=0$ for a no/negative vote; $N=$ the number of votes). $V_{i}$ can be a single vote or group of votes (for a single vote $Y_{j}$ $=1$ or 0 and $n=1$ ).
} 
In other words, elaborating on equation 1 we want to estimate (dropping the $i$ subscript)

$$
V(S)=f(P, D, L P, C, I)
$$

As indicated above, although this is generally estimated as $V=g(P, D, L P, C, A D A)$, where ADA is used a proxy for the hard to measure $I$, we have developed an alternative residualized $I^{*}$. Thus, we conjecture:

$$
V(S)=h\left(P^{*}, D^{*}, L P^{*}, C^{*}, I^{*}\right)
$$

Now the structure of equation (18) is not quite the same as the equations in stage 1 . Here the residualization of ideology need not be orthogonal to the other explanatory variables if they were not included in the equations used to estimate $I^{*}$ which allows $I^{*}$ potentially to have indirect effects. Further, recall that we have a measure of ideology which is "purged" of indirect effects (on ADA).

\section{An Application to Illustrate Stage 2}

Finally, let us see the effect of utilizing both our measure of ideology and the "standard" measure. To do this, we report the findings of a preliminary attempt to explain (or predict) voting on issues of concern to organized labor. ${ }^{41}$ Here we utilize the evaluation, or rating, of the senators by the AFLCIO (i.e., their COPE scores) as the dependent variable and develop two models (see Table 4). In one we utilize our measure of ideology $\left(I^{*}\right)$ and in the other we utilize the traditional ADA measure.

\footnotetext{
${ }^{4}$ The reader may be interested in contrasting our model with two previous studies which used the standard ADA approach to explain voting on minimum wage legislation (Kau \& Rubin, 1978; Silberman \& Durden, 1976). Interested readers may also wish to obtain ideological ratings which take into account some coalitional characteristics as well as ratings for members of the House. These can be obtained from the authors.
}

Table 4. Comparing the Models Applied to Labor Issues:

\begin{tabular}{|c|c|c|c|c|}
\hline Independent variable & Coefficient & t-Statistic & PROB $>|T|$ & $\begin{array}{l}\text { Standardized } \\
\text { Coefficients }\end{array}$ \\
\hline \multicolumn{5}{|c|}{ Independent variable: I* } \\
\hline $\begin{array}{l}\text { Intercept } \\
\text { Party } \\
\text { YOff } \\
\text { PMan } \\
\text { PAFLCIO } \\
\text { I* }\end{array}$ & $\begin{array}{r}-0.086 \\
0.475 \\
-.011 \\
0.003 \\
0.029 \\
0.174\end{array}$ & $\begin{array}{r}-1.2 \\
11.3 \\
-6.0 \\
1.7 \\
13.4 \\
4.9\end{array}$ & $\begin{array}{l}0.2219 \\
0.0001 \\
0.0001 \\
0.0863 \\
0.0001 \\
0.0001\end{array}$ & $\begin{array}{c}-7.25 \times \mathrm{E}-10 \\
.343 \\
-.173 \\
.052 \\
.420 \\
.148\end{array}$ \\
\hline \multicolumn{5}{|l|}{$R^{2}=.25$} \\
\hline $\begin{array}{l}\text { Independent variable: } \\
\text { Intercept } \\
\text { Party } \\
\text { YOff } \\
\text { PMan } \\
\text { PAFLCIO } \\
\text { ADA }\end{array}$ & $\begin{array}{r}-0.458 \\
0.273 \\
-0.008 \\
-0.001 \\
0.025 \\
0.010\end{array}$ & $\begin{array}{r}-6.9 \\
7.6 \\
-5.0 \\
-0.9 \\
12.8 \\
16.1\end{array}$ & $\begin{array}{l}0.0001 \\
0.0001 \\
0.0001 \\
0.3640 \\
0.0001 \\
0.0001\end{array}$ & $\begin{array}{c}-3.88 \times E-09 \\
0.20 \\
-0.13 \\
-0.02 \\
0.36 \\
0.43\end{array}$ \\
\hline \multicolumn{5}{|l|}{$R^{2}=.40$} \\
\hline $\begin{array}{l}\text { Without ideology } \\
\text { Intercept } \\
\text { Party } \\
\text { YOff } \\
\text { PMan } \\
\text { PAFLCIO }\end{array}$ & $\begin{array}{r}0.028 \\
0.400 \\
-0.011 \\
0.003 \\
0.027\end{array}$ & $\begin{array}{r}0.4 \\
10.1 \\
-\quad 5.9 \\
1.6 \\
12.6\end{array}$ & $\begin{array}{l}0.6748 \\
0.0001 \\
0.0001 \\
0.1019 \\
0.0001\end{array}$ & $\begin{array}{c}2.38 \times \mathrm{E}-10 \\
0.29 \\
-0.17 \\
0.05 \\
0.39\end{array}$ \\
\hline$R^{2}=.23$ & & & & \\
\hline
\end{tabular}

ADA vs. I* as Independent Variables Explaining Cope Scores $(n=967)^{\mathrm{a}}$

${ }^{\mathrm{a}} \mathrm{Here}$ the actual dependent variable is the probit transformation of the COPE scores. 
Now the effect of the operationalization is made clear. When ADA is used, party's effect is decreased considerably, as are the effects of all of the other variables, which can be seen by comparing the standardized weights in Tables 4.1 and 4.2. This result occurs because of the strong correlations between ADA ratings and the other included variables. On the other hand, because ADA ratings are a surrogate for many of the characteristics of the state, replacing ADA by $I^{*}$ decreases the explained variance. Note that one could reintroduce these demographic and economic characteristics of the state now without fear of their correlation with the residualized measure of ideology.

Along with Robert Cameron Mitchell, we have applied the technique to a second substantive question: legislators' voting on environmental issues (Oppenheimer, Mitchell, \& Carson, in press). The parallel results there form an interesting contrast. $I^{*}$ there is far more effective as an explanatory variable than it is in explaining COPE scores. Using party and the percentage of the state population who are members of environmental groups along with ideology, we found $I^{*}$ increased $R^{2}$ from .16 to .24 . Further, it yielded an equation which quite sensibly indicated that all three variables were highly significant (with 479 degrees of freedom, $t$ was above 7 for all coefficients). This was in contrast to the results when ADA was used instead of $I^{*}$. ADA, as a surrogate for all the socioeconomic and political characteristics of the state yielded a very improved $R^{2}(.51)$. But it so distorted the weights that party's coefficient was significant only at a .07 level. Here again, one can reintroduce the demographic and economic characteristics of the state, with $I^{*}$, and without fear that the correlation with $I^{*}$ will lead to difficulties of interpretation.

\section{Conclusions}

We have developed a procedure for extracting a politician's ideological leaning, relative to his or her political environment, which may be interpreted in various ways. If the electoral environment is defined strictly as the politician's electorate, it can be thought of as a deviation from the electoral unit from which he or she is elected, as conceived of by Johannes and McAdams (1981). But if we define the political environment more broadly, there are many possible interpretations of this variable. It could be personal ideology, or purchased positions by forces outside of the incumbent's electorate, or positions taken for national political considerations (e.g., to go along with the presidency), depending upon which variables are brought to bear. All of these interpretations can be tested in their own right. But that would constitute a further article (see Oppen- heimer, Mitchell, \& Carson, in press). Any of these interpretations would make some politicians who have liberal records look conservative, namely those politicians who score high on ADA ratings, but come from even more liberal electorates. Similarly, some politicians from conservative districts, with less conservative records, will appear liberal. Hence, this method is likely to stretch the theoretical understanding and conceptualization of ideology which we hold.

Let us review the assumptions underlying this technique. First, we assume that the residuals (for example, as calculated in Table 1 above) contain only a random error term and our $I^{*}$ variable. This is a rebuttable presumption. But at this point in time, the burden of proof seems to be on the critic. After all, any variable conjectured to be contained in the residual can be tested for, and the new residual calculated to examine its nature. Thus, the general technique does not require that we have correctly isolated $I^{*}$ at this point. Second, we assume that each individual's personal ideology is stable. This requirement is endemic to the procedure, as is the assumption that the actual error terms are uncorrelated over time (and therefore that their correlation is an artifact of the other variable, $I^{*}$, contained in the residual). These assumptions permit the developmment of an alternative measure for ideology which yields a number of benefits including an ability to assess, realistically, the relative importance of the various factors determining a legislator's vote.

The technique has other practical significance. It would permit, for example, interest groups to assess which incumbents are "friendly" and ought to be supported. Rather than identifying those with the highest ADA rating as the most liberal, we now identify those who go furthest to the left of their constituents as the most liberal. This permits us to relativize the voting of the legislators to their constituency and their pressures. Hence we see who is most likely to go out on a limb because of personal political feelings. Similar work could be done for other interest group scores.

\section{References}

Barone, M., Ujifusa, G., \& Matthews, D. The almanac of American politics. Boston: Gambit, 1970, 1972, 1974; New York: Dutton, 1976, 1978, 1980 and 1982.

Bernstein, R. A., \& Horn, S. R. Explaining House voting on energy policy: ideology and the conditional effects of party and district economic interests. Western Political Quarterly, 1981, 34, 235-245.

Chamberlain, G. Education, income, ability revisited. Journal of Econometrics, 1977, 5, 241-254.

Chappell, H. W., Jr. Campaign contributions and voting on the cargo preference bill: a comparison of 
simultaneous models. Public Choice, 1981, 36, 301-312. (a)

Chappell, H. W., Jr. Conflict of interest and congressional voting: a note. Public Choice, 1981, 37, 331-336. (b)

Downs, A. J. An economic theory of democracy. New York: Harper \& Row, 1957.

Dunlop, R. E., \& Allen, M. P. Partisan differences on environmental issues: a congressional roll-call analysis. Western Political Quarterly, 1976, 29, 384-397.

Fiorina, M. P. Comments. In C. S. Russell (Ed.), Collective decision making. Baltimore: Johns Hopkins University Press (for Resources for the Future), 1979.

Goldberger, A. S. Econometric theory. New York: Wiley, 1964.

Hanushek, E. A., \& Jackson, J. E. Statistical methods for social scientists. New York: Academic Press, 1977.

Johannes, J. R., \& McAdams, J. C. The congressional incumbency effect: is it casework, policy compatibility, or something else? an examination of the 1978 election. American Journal of Political Science, $1981,25,512-541$.

Judge, G. G. et al. The theory and practice of econometrics. New York: Wiley, 1980.

Judge, G. G. et al. An introduction to the theory and practice of econometrics. New York: John Wiley, 1982.

Kalt, J. P. The economics and politics of oil price regulation. Cambridge, Mass.: MIT Press, 1981.

Kalt, J. P. Oil and ideology in the U.S. Senate. The Energy Journal, 1982, 3, 141-166.

Kau, J. B., Keenan, D., \& Rubin, P. H. A general equilibrium model of congressional voting. Quarterly Journal of Economics, 1982, 271-293.

Kau, J. B., \& Rubin, P. H. Voting on minimum wages: a time-series analysis. Journal of Political Economy, 1978, 86, 337-341.

Kau, J. B., \& Rubin, P. H. Self-interest, ideology, and logrolling in congressional voting. The Journal of Law and Economics, 1979, 22, 365-384. (a)

Kau, J. B., \& Rubin, P. H. Public interest lobbies: membership and influence. Public Choice, 1979, 34, 45-54. (b)

Kenski, H. C., \& Kenski, M. C. Partisanship, ideology, and constituency differences on environmental issues in the U.S. House of Representatives: 1973-78. Policy Studies Journal, 1980, 9, 325-335.
Kingdon, J. W. Models of legislative voting. The Journal of Politics, 1977, 39, 563-595.

Kushner, H. W. Electoral margins and ideological voting. Review of Public Data Use, 1975, 3, 23-27.

Lindgrem, B. W., \& McElrath, G. W. Introduction to probability and statistics, 3rd ed. New York: Macmillan, 1969.

Lopreato, S. C., \& Smoller, F. Explaining energy votes in the ninety-fourth Congress. Center for Energy Studies, The University of Texas at Austin, Policy Study No. 1, 1978.

MacRae, D. Issues and parties in legislative voting: methods of statistical analysis. New York: Harper and Row, 1970.

Markus, G. B. Electoral coalitions and Senate roll call behavior: an ecological analysis. American Journal of Political Science, 1974, 18, 595-607.

Matthews, D. U.S. senators and their world. Chapel Hill, N.C.: University of North Carolina Press, 1960.

Mayhew, D. R. The electoral connection. New Haven, Conn.: Yale University Press, 1974.

Oppenheimer, J. A. Some political implications of "vote trading and the voting paradox: a proof of logical equivalence." American Political Science Review, 1975, 69, 963-966.

Oppenheimer, J. A., Mitchell, R. C., \& Carson, R. Explaining congressional environmental voting. 1984, unpublished.

Poole, K. T. Dimensions of interest group evaluation of the U.S. Senate, 1969-1978. American Journal of Political Science, 1981, 25, 49-67.

Ridker, R. G., \& Henning, J. A. The determinants of residential property values with special reference to air pollution..Review of Economics and Statistics, 1967, 49, 246-257.

Shreck, A. E. Minerals yearbook: 1975. U.S. Department of the Interior, Bureau of Mines, Washington, D.C., 1977.

Silberman, J. I., \& Durden, G. C. Determining legislative preferences on the minimum wage: an economic approach. Journal of Political Economy, 1976, 84, 317-329.

Weisberg, H. F. Evaluating theories of congressional roll-call voting. American Journal of Political Science, 1978, 22, 554-557.

Wittman, D. Candidates with policy preferences: a dynamic model. Journal of Economic Theory, 1977, 14, 180-189. 
http://www.jstor.org

\title{
LINKED CITATIONS
}

- Page 1 of 5 -

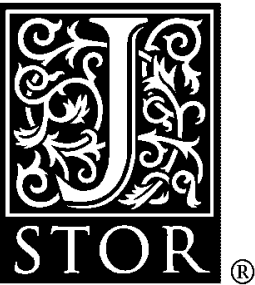

You have printed the following article:
A Method of Estimating the Personal Ideology of Political Representatives
Richard T. Carson; Joe A. Oppenheimer
The American Political Science Review, Vol. 78, No. 1. (Mar., 1984), pp. 163-178.
Stable URL:
http://links.jstor.org/sici?sici=0003-0554\%28198403\%2978\%3A1\%3C163\%3AAMOETP\%3E2.0.CO\%3B2-B

This article references the following linked citations. If you are trying to access articles from an off-campus location, you may be required to first logon via your library web site to access JSTOR. Please visit your library's website or contact a librarian to learn about options for remote access to JSTOR.

\section{[Footnotes]}

\author{
${ }^{1}$ Models of Legislative Voting \\ John W. Kingdon \\ The Journal of Politics, Vol. 39, No. 3. (Aug., 1977), pp. 563-595. \\ Stable URL: \\ http://links.jstor.org/sici?sici=0022-3816\%28197708\%2939\%3A3\%3C563\%3AMOLV\%3E2.0.CO\%3B2-U \\ ${ }^{1}$ Evaluating Theories of Congressional Roll-Call Voting \\ Herbert F. Weisberg \\ American Journal of Political Science, Vol. 22, No. 3. (Aug., 1978), pp. 554-577. \\ Stable URL: \\ http://links.jstor.org/sici?sici=0092-5853\%28197808\%2922\%3A3\%3C554\%3AETOCRV\%3E2.0.CO\%3B2-I

\footnotetext{
${ }^{1}$ Electoral Coalitions and Senate Roll Call Behavior: An Ecological Analysis

Gregory B. Markus

American Journal of Political Science, Vol. 18, No. 3. (Aug., 1974), pp. 595-607.

Stable URL:

http://links.jstor.org/sici?sici=0092-5853\%28197408\%2918\%3A3\%3C595\%3AECASRC\%3E2.0.CO\%3B2-E

${ }^{2}$ Determining Legislative Preferences on the Minimum Wage: An Economic Approach Jonathan I. Silberman; Garey C. Durden

The Journal of Political Economy, Vol. 84, No. 2. (Apr., 1976), pp. 317-330.

Stable URL:

http://links.jstor.org/sici?sici=0022-3808\%28197604\%2984\%3A2\%3C317\%3ADLPOTM\%3E2.0.CO\%3B2-R
}

NOTE: The reference numbering from the original has been maintained in this citation list. 
http://www.jstor.org

\section{LINKED CITATIONS}

- Page 2 of 5 -

\footnotetext{
${ }^{4}$ Electoral Coalitions and Senate Roll Call Behavior: An Ecological Analysis Gregory B. Markus

American Journal of Political Science, Vol. 18, No. 3. (Aug., 1974), pp. 595-607.

Stable URL:

http://links.jstor.org/sici?sici=0092-5853\%28197408\%2918\%3A3\%3C595\%3AECASRC\%3E2.0.CO\%3B2-E
}

\footnotetext{
${ }^{4}$ Some Political Implications of "Vote Trading and the Voting Paradox: A Proof of Logical Equivalence:" A Comment

Joe Oppenheimer

The American Political Science Review, Vol. 69, No. 3. (Sep., 1975), pp. 963-966.

Stable URL:

http://links.jstor.org/sici?sici=0003-0554\%28197509\%2969\%3A3\%3C963\%3ASPIO\%22T\%3E2.0.CO\%3B2-O
}

\section{${ }^{5}$ Dimensions of Interest Group Evaluation of the U.S. Senate, 1969-1978}

Keith T. Poole

American Journal of Political Science, Vol. 25, No. 1. (Feb., 1981), pp. 49-67.

Stable URL:

http://links.jstor.org/sici?sici=0092-5853\%28198102\%2925\%3A1\%3C49\%3ADOIGEO\%3E2.0.CO\%3B2-8

${ }^{8}$ The Determinants of Residential Property Values with Special Reference to Air Pollution Ronald G. Ridker; John A. Henning

The Review of Economics and Statistics, Vol. 49, No. 2. (May, 1967), pp. 246-257.

Stable URL:

http://links.jstor.org/sici?sici=0034-6535\%28196705\%2949\%3A2\%3C246\%3ATDORPV\%3E2.0.CO\%3B2-H

\footnotetext{
${ }^{13}$ The Congressional Incumbency Effect: Is It Casework, Policy Compatibility, or Something Else? An Examination of the 1978 Election

John R. Johannes; John C. McAdams

American Journal of Political Science, Vol. 25, No. 3. (Aug., 1981), pp. 512-542.

Stable URL:

http://links.jstor.org/sici?sici=0092-5853\%28198108\%2925\%3A3\%3C512\%3ATCIEII\%3E2.0.CO\%3B2-M
}

\footnotetext{
${ }^{24}$ A General Equilibrium Model of Congressional Voting

James B. Kau; Donald Keenan; Paul H. Rubin

The Quarterly Journal of Economics, Vol. 97, No. 2. (May, 1982), pp. 271-293.

Stable URL:

http://links.jstor.org/sici?sici=0033-5533\%28198205\%2997\%3A2\%3C271\%3AAGEMOC\%3E2.0.CO\%3B2-3
}

NOTE: The reference numbering from the original has been maintained in this citation list. 
http://www.jstor.org

\title{
LINKED CITATIONS
}

- Page 3 of 5 -

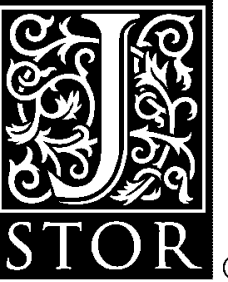

\section{${ }^{32}$ A General Equilibrium Model of Congressional Voting}

James B. Kau; Donald Keenan; Paul H. Rubin

The Quarterly Journal of Economics, Vol. 97, No. 2. (May, 1982), pp. 271-293.

Stable URL:

http://links.jstor.org/sici?sici=0033-5533\%28198205\%2997\%3A2\%3C271\%3AAGEMOC\%3E2.0.CO\%3B2-3

${ }^{41}$ Voting on Minimum Wages: A Time-Series Analysis

James B. Kau; Paul H. Rubin

The Journal of Political Economy, Vol. 86, No. 2, Part 1. (Apr., 1978), pp. 337-342.

Stable URL:

http://links.jstor.org/sici?sici=0022-3808\%28197804\%2986\%3A2\%3C337\%3AVOMWAT\%3E2.0.CO\%3B2-0

${ }^{41}$ Determining Legislative Preferences on the Minimum Wage: An Economic Approach Jonathan I. Silberman; Garey C. Durden

The Journal of Political Economy, Vol. 84, No. 2. (Apr., 1976), pp. 317-330.

Stable URL:

http://links.jstor.org/sici?sici=0022-3808\%28197604\%2984\%3A2\%3C317\%3ADLPOTM\%3E2.0.CO\%3B2-R

\section{References}

The Congressional Incumbency Effect: Is It Casework, Policy Compatibility, or Something Else? An Examination of the 1978 Election

John R. Johannes; John C. McAdams

American Journal of Political Science, Vol. 25, No. 3. (Aug., 1981), pp. 512-542.

Stable URL:

http://links.jstor.org/sici?sici=0092-5853\%28198108\%2925\%3A3\%3C512\%3ATCIEII\%3E2.0.CO\%3B2-M

\author{
A General Equilibrium Model of Congressional Voting \\ James B. Kau; Donald Keenan; Paul H. Rubin \\ The Quarterly Journal of Economics, Vol. 97, No. 2. (May, 1982), pp. 271-293. \\ Stable URL: \\ http://links.jstor.org/sici?sici=0033-5533\%28198205\%2997\%3A2\%3C271\%3AAGEMOC\%3E2.0.CO\%3B2-3
}

NOTE: The reference numbering from the original has been maintained in this citation list. 
http://www.jstor.org

\title{
LINKED CITATIONS
}

- Page 4 of 5 -

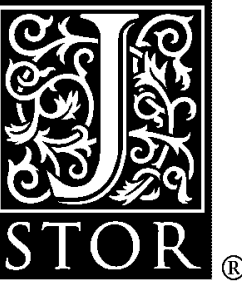

\author{
Voting on Minimum Wages: A Time-Series Analysis \\ James B. Kau; Paul H. Rubin \\ The Journal of Political Economy, Vol. 86, No. 2, Part 1. (Apr., 1978), pp. 337-342. \\ Stable URL: \\ http://links.jstor.org/sici?sici=0022-3808\%28197804\%2986\%3A2\%3C337\%3AVOMWAT\%3E2.0.CO\%3B2-0
}

\section{Models of Legislative Voting}

John W. Kingdon

The Journal of Politics, Vol. 39, No. 3. (Aug., 1977), pp. 563-595.

Stable URL:

http://links.jstor.org/sici?sici=0022-3816\%28197708\%2939\%3A3\%3C563\%3AMOLV\%3E2.0.CO\%3B2-U

Electoral Coalitions and Senate Roll Call Behavior: An Ecological Analysis

Gregory B. Markus

American Journal of Political Science, Vol. 18, No. 3. (Aug., 1974), pp. 595-607.

Stable URL:

http://links.jstor.org/sici?sici=0092-5853\%28197408\%2918\%3A3\%3C595\%3AECASRC\%3E2.0.CO\%3B2-E

Some Political Implications of "Vote Trading and the Voting Paradox: A Proof of Logical Equivalence:" A Comment

Joe Oppenheimer

The American Political Science Review, Vol. 69, No. 3. (Sep., 1975), pp. 963-966.

Stable URL:

http://links.jstor.org/sici?sici=0003-0554\%28197509\%2969\%3A3\%3C963\%3ASPIO\%22T\%3E2.0.CO\%3B2-O

Dimensions of Interest Group Evaluation of the U.S. Senate, 1969-1978

Keith T. Poole

American Journal of Political Science, Vol. 25, No. 1. (Feb., 1981), pp. 49-67.

Stable URL:

http://links.jstor.org/sici?sici=0092-5853\%28198102\%2925\%3A1\%3C49\%3ADOIGEO\%3E2.0.CO\%3B2-8

The Determinants of Residential Property Values with Special Reference to Air Pollution Ronald G. Ridker; John A. Henning

The Review of Economics and Statistics, Vol. 49, No. 2. (May, 1967), pp. 246-257.

Stable URL:

http://links.jstor.org/sici?sici=0034-6535\%28196705\%2949\%3A2\%3C246\%3ATDORPV\%3E2.0.CO\%3B2-H

NOTE: The reference numbering from the original has been maintained in this citation list. 
http://www.jstor.org

\section{LINKED CITATIONS \\ - Page 5 of 5 -}

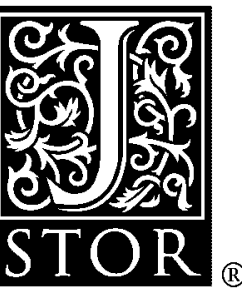

Determining Legislative Preferences on the Minimum Wage: An Economic Approach Jonathan I. Silberman; Garey C. Durden

The Journal of Political Economy, Vol. 84, No. 2. (Apr., 1976), pp. 317-330.

Stable URL:

http://links.jstor.org/sici?sici=0022-3808\%28197604\%2984\%3A2\%3C317\%3ADLPOTM\%3E2.0.CO\%3B2-R

\section{Evaluating Theories of Congressional Roll-Call Voting}

Herbert F. Weisberg

American Journal of Political Science, Vol. 22, No. 3. (Aug., 1978), pp. 554-577.

Stable URL:

http://links.jstor.org/sici?sici=0092-5853\%28197808\%2922\%3A3\%3C554\%3AETOCRV\%3E2.0.CO\%3B2-I

NOTE: The reference numbering from the original has been maintained in this citation list. 